\title{
The Difference between Placebo and Energy Drinking Consumption towards Aerobic Endurance
}

\author{
Zarwan, Sefri Hardiansyah, Ade Zalindro, Fella Maifitri \\ Department of Physical Education, Faculty of Sport Science, Universitas Negeri Padang, Indonesia \\ *Corresponding author: zarwan@fik.unp.ac.id
}

Article history: Received: 01 January 2020 Received in revised form: 09 February 2020 Accepted: 02 March 2020 Published online: 26 August 2020

\begin{abstract}
An issue of this research is the aerobic endurance of students categorized low during the formation of physical conditions so that many students consume energy drinks to improve the aerobic endurance capability. However, this is still an assumption needed to prove by giving another comparative drink (placebo). The purpose of this research is to compare the effect of placebo and energy drinks consumption to aerobic endurance capability. It was quasiexperiment research using two types of substances: placebo consumed by experimental group (X1) and energy drinks consumed by the control group (X2). The population of this study was a group of 40 students. Samples were 36 students chosen by purposive sampling technique. Division of the group in a random way, the instrument used was Cooper run test $2.4 \mathrm{~km}$. Data were analyzed using the test of different independent samples. The results of this study obtained the mean of 1.03 for the placebo group and the mean of 1.10 for the energy drink group. The statistical testobtainedtobserved0.14<ttable1.69 so that it can be concluded that the effects given by the consumption of placebo and energy drinks are not significantly different.
\end{abstract}

Keywords: placebo, energy drink, aerobic endurance

(C) 2020 Penerbit UTM Press. All rights reserved

\subsection{BACKGROUND OF STUDY}

The physical condition is essential for students of the Faculty of Sports Sciences, especially those who follow the course of physical conditions. To be able to follow the lecture to the maximum, physical condition is needed, especially endurance, because the course demands physical in prime condition. The importance of endurance for students of the Faculty of Sport Science becomes a problem for students so that many students do various ways to improve their endurance capacity. One of the efforts that students often do is to consume energy drinks. Most students believe the effect of energy drinks enhance their endurance capability so that they consume energy drinks as compulsory every day. The physical condition course requires students to be able to meet the maximum physical ability so that it needs excellent endurance skills. Students claimed that they feel an increase in endurance if consuming energy drinks so that they can follow the lecture with maximum even able to follow other activities outside the lecture.

It should be further reviewed because energy drinks consumed by the students might not have any effect on the ability of aerobic endurance, and it might be only a suggestion from the mind of students so that their bodies follow what the suggestion said. The main focus of this study is the low aerobic endurance of students, and many students consume energy drinks to improve their endurance abilities. In contrast, energy drinks have not been scientifically proven to increase endurance abilities. Therefore, it is necessary to conduct further research on the effects given by the energy drink and placebo. Placebo is a dummy drug that can affect a person's psychological state $^{1}$

\subsection{RESEARCH OBJECTIVES}

The purpose of this research is to compare the influences given by placebo and energy drinks to the enhancement of aerobic endurance capabilities.

\section{Placebo}

Placebo is an empty drug commonly administered by doctors to patients suffering from an illness. It is an empty drug that is familiarized given to patients to cure certain diseases ${ }^{1}$. It is something that can change a person's psychological response ${ }^{2}$. It is also commonly referred to as an empty drug because the placebo does not contain any active ingredients intended to enhance the ability of the body's function. 
From the above two definitions, it can be said that placebo is an empty substance/drug that does not contain active ingredients and only gives a psychological effect of suggestive to the belief in the benefits of consuming such substances.

Placebo has several benefits, a placebo effect, i.e., positive results brought purely from the belief that a person has received a positive intervention $^{3}$. A person who believes in a placebo can change their steps quickly ${ }^{4}$. So, the benefit of a placebo is to increase confidence in one's self to be able to do more normal ability.

Placebo given in the study is a substance that does not contain elements that can increase the ability of the aerobic endurance but only ordinary substances. However, with the explanation given to the subject first, then it is believed will be able to provide a suggestion to the subject that the substance can help to improve endurance.

\section{Energy Drink}

\section{i. Definition Of Energy Drinks}

Energy drinks are beverages manufactured by factories containing substances that are suspected to improve the ability of physical conditions. Energy drinks are drinks that refresh consumers with a combination of sugar, cafes, and other ingredients ${ }^{5}$. According to Chesney, in addition to containing caffeine, energy drinks also contain taurine, which can become toxic substances and oxidants in the human body ${ }^{6}$. From the above two opinions, it can be understood that energy drink is a drink containing caffeine that can improve the physical ability and taurine that can become toxic (oxidant) in the human body.

\section{ii. Energy Drink Benefits}

Energy drinks are usually consumed with to increase the ability to exercise, and the primary substance found in energy drinks is caffeine, so that it is suspected to improve the ability of physical conditions ${ }^{7}$. One of the main reasons for consuming energy drinks is to improve exercise, improve sports performance, and to facilitate faster training adaptation ${ }^{8}$. From the two opinions, it can be understood that energy drinks have a positive impact on the human body because it contains caffeine and contains substances that can improve the body's performance in exercising. The effect of energy drinks on running performance remains unclear ${ }^{6}$. Therefore, it is necessary to do in-depth research. The energy drink consists of several brands and flavors to make the community interested in consuming such beverages, including students. Many of these students opt to use energy drinks as supplements to increase or enhance aerobic endurance capabilities.

\section{iii. Energy Drink Content}

The content contained in energy drinks varies according to the brand of the energy drink producers. However, some content is prevalent in energy drinks, including caffeine, taurine, guarana, carnitine, ginseng, and Ginkgo Biloba.

\section{a. Aerobic Endurance}

Aerobic Endurance is a person's capacity to withstand fatigue. Aerobic endurance is not only significant in competitive performance for most sports branches but is a very decisive factor for the performance of athletes in the exercise and overall capacity.

There are several different terms commonly used for aerobic endurance, including aerobic fitness, cardiovascular endurance, cardiovascular fitness, cardiorespiratory fitness, physical work capacity, aerobic capacity, and maximal oxygen uptake. Cardiovascular endurance is the ability of the lungs, heart, blood vessels, and blood to convey adequate amounts of oxygen and nutrient substances to cells that work to meet the needs of long-lasting physical activity 9 .

Aerobic Endurance, according to Hazeldine, is associated with the process of sucking, transporting, and using oxygen ${ }^{9}$. Aerobic endurance is endurance or explosive power during a long-distance run and is classified as aerobic endurance ${ }^{10}$.

It is concluded that aerobic endurance is an intricate component of physical fitness. It involves the interaction of several physiological processes in the cardiovascular, including lung capacity to Inhale oxygen, blood capacity in the lungs to absorb oxygen, the capacity of the heart to pump blood that contains oxygen to the muscle tissues and muscle tissue capacity to absorb oxygen from the blood and use it to produce energy.

Aerobic Endurance is one of the essential phases of physical fitness. This aerobic endurance is an essential requirement for sports endurance branches. As the most suitable illustration is, the aerobic endurance capacity precisely determines the marathon running capability that lasts in a few hours.

\subsection{METHODOLOGY}

This type of research is a quasi-experiment using energy drinks as an experimental and placebo variable as a control variable. The population amounted to 46 people, and the sample withdrawal technique used is a sampling purposive that is a student who consumes energy drinks and has a minimum age of 18 years, so samples amounted to 36 peoples consisting of 18 peoples group of drinks Energy and 18 peoples in placebo. The instrument used in this research is to use the Cooper test. Data analysis techniques using different tests of $t$ independent samples. 


\subsection{FINDINGS}

\section{Data description}

\section{Placebo Group}

Based on the aerobic endurance measurements that have been performed against 18 people, the subject is obtained preliminary data: The highest score is 21.43 , and the lowest score is 10.17 , averaging 13.37, the standard deviation is 3.10. and final data: Highest score 19.11 and lowest score 9.47, average 12.34, standard deviation 2.77. An average increase of 1.03. More complete measurement results can be seen in table 1.

Table 1 Placebo Group Data

\begin{tabular}{lllll}
\hline Interval Class & $\begin{array}{l}\text { Pre Test } \\
\text { Frequency } \\
\text { Absolute }\end{array}$ & $\begin{array}{l}\text { Frequency } \\
\text { Relative }\end{array}$ & $\begin{array}{l}\text { Post Test } \\
\text { Frequency } \\
\text { Absolute }\end{array}$ & $\begin{array}{l}\text { Frequency Relative } \\
(\%)\end{array}$ \\
\hline$>15.31$ & 3 & 16.67 & 1 & 5.56 \\
$12.11-15.30$ & 5 & 27.78 & 4 & 22.22 \\
$10.49-12.10$ & 7 & 38.89 & 8 & 44.44 \\
$09.41-10.48$ & 2 & 11.11 & 4 & 22.22 \\
$08.37-09.40$ & 1 & 5.56 & 1 & 5.56 \\
$<08.37$ & 0 & 0 & 0 & 0 \\
Total & 18 & 100 & 18 & 100 \\
\hline
\end{tabular}

From table 1 above, it can be seen that the interval class of $>15.31$, in the pre-test, there are three students, while in the post-test data is one student. At the interval of 12.11-15.30, there are five students in the pre-test and are four students in the post-test. At intervals of 10.49-12.10, there are seven students in the pre-test and are eight students in the post-test. At an interval level of 09.41-10.48, there are two students in the pre-test and are four students in the post-test. At the interval class of 08.37-09.40, there is one student in the pre-test and is also1 students in the post-test. At an interval class of $>08.37$, no samples that have durability in that category. The results of the placebogroup endurance measurement classification can be seen in Figure 1.

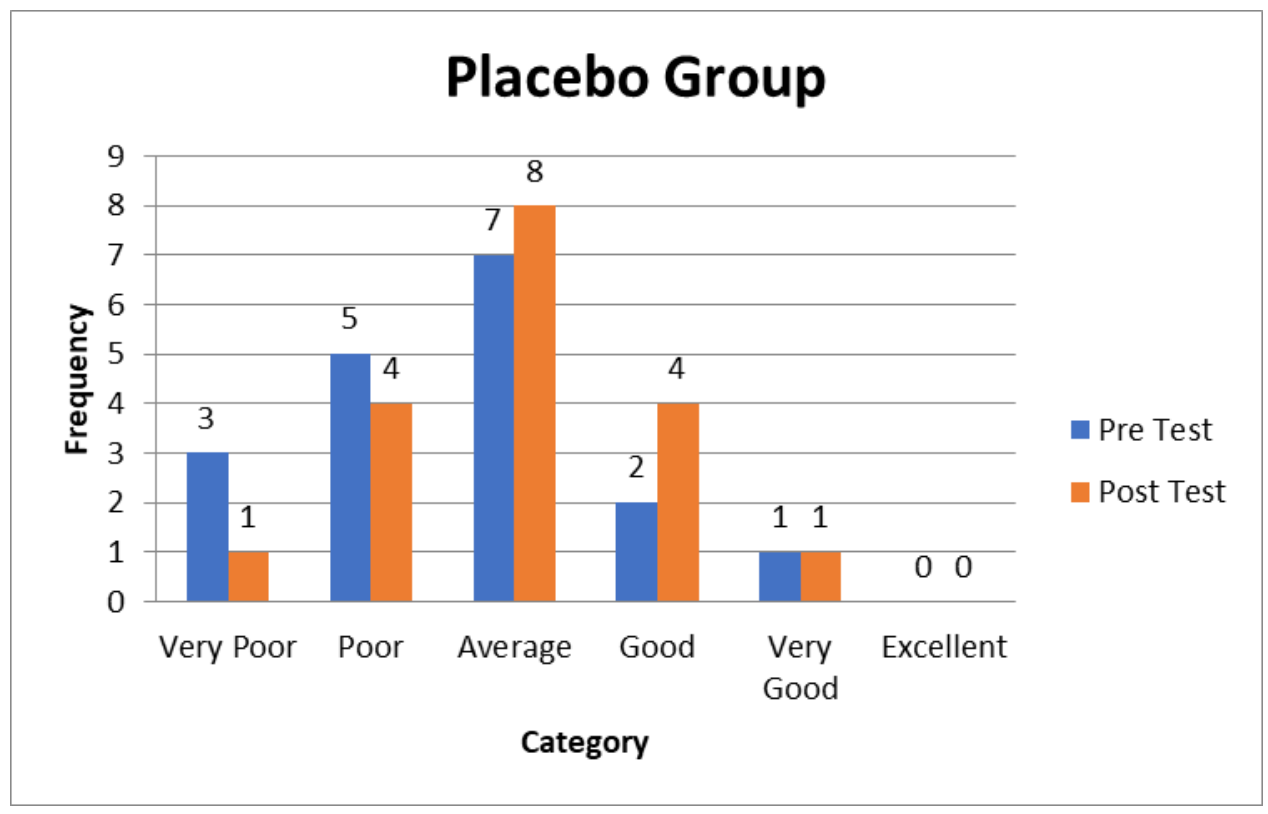

Figure 1 Aerobic Endurance in the Placebo group

\section{Energy Drink Group}

Based on the aerobic endurance measurements that have been performed against 18 students obtained preliminary data: The highest score is 23.01, and the lowest score is 11.1, averaging 14.27, the standard deviation is 3.45. and final data: Highest score 20.52 and lowest score 10.06, average 13.18, standard deviation 3.04. An average increase of 1.10. More complete measurement results can be seen in table 2. 
Table 2 Energy Drink Group Data

\begin{tabular}{lllll}
\hline Interval Class & $\begin{array}{l}\text { Pre Test } \\
\text { Frequency } \\
\text { Absolute }\end{array}$ & $\begin{array}{l}\text { Frequency } \\
\text { Relative }\end{array}$ & $\begin{array}{l}\text { Post Test } \\
\text { Absolute }\end{array}$ & $\begin{array}{l}\text { Frequency Relative } \\
(\%)\end{array}$ \\
\hline$>15.31$ & 6 & 33.33 & 5 & 27.78 \\
$12.11-15.30$ & 6 & 33.33 & 5 & 27.78 \\
$10.49-12.10$ & 6 & 33.33 & 4 & 22.22 \\
$09.41-10.48$ & 0 & 0.00 & 4 & 22.22 \\
$08.37-09.40$ & 0 & 0.00 & 0 & 0.00 \\
$<08.37$ & 0 & 0.00 & 0 & 0.00 \\
Total & 18 & 100 & 18 & 100 \\
\hline
\end{tabular}

From table 2 above, it can be seen that at an interval class of $>15.31$, there are six students in the pre-test and are five students in the posttest. At the interval class of 12.11-15.30, there are six students in the pre-test and are five students in the post-test. At the interval class of 10.49-12.10, there are six students in the pre-test and are four students in the post-test. At the interval class of 09.41-10.48, there are no students in this category in the pre-test and are four students in the post-test. Results measurement of aerobic endurance of energy drink group can be seen in Figure 2.

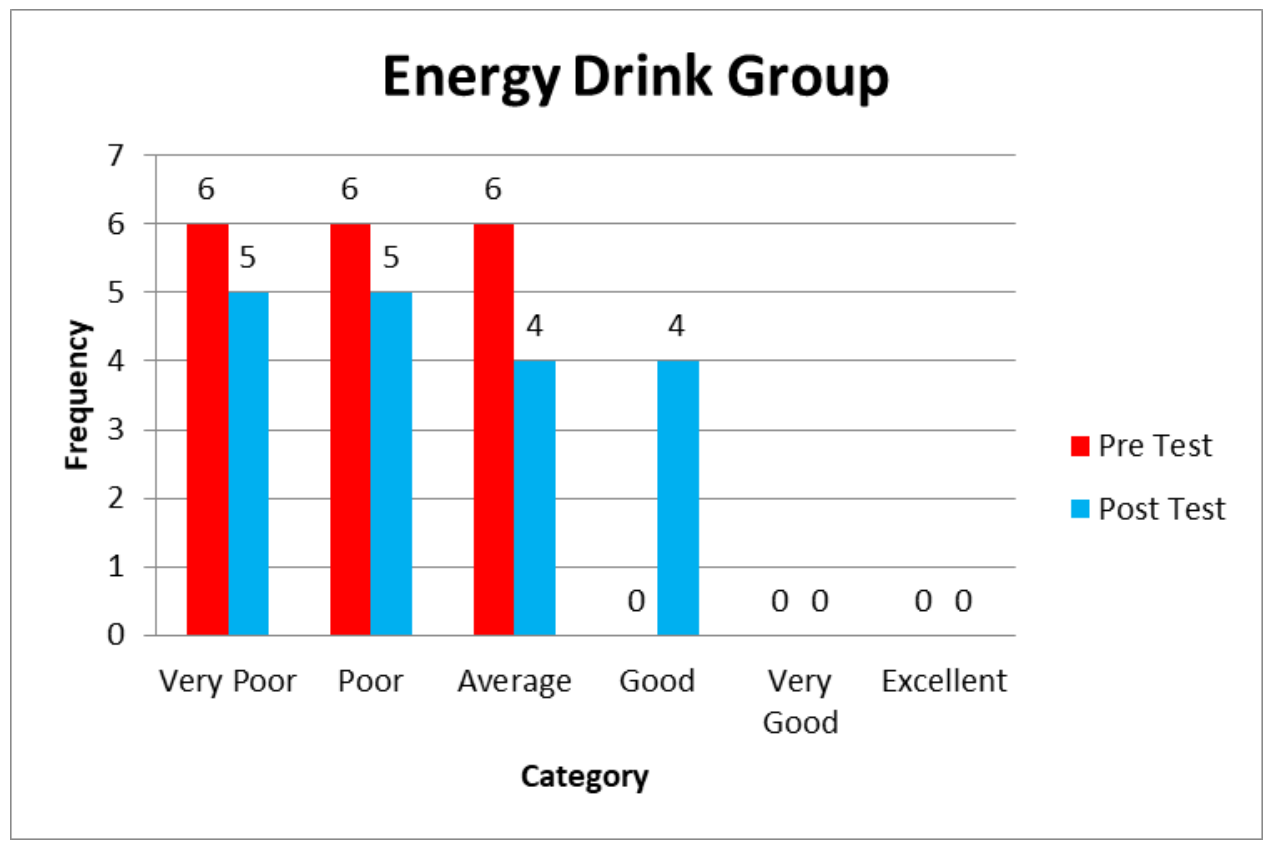

Figure 2 Aerobic Endurance Ability Energy Drink Group

\section{Normality test}

Based on the normality test performed using the Liliefors test, the $\mathrm{L}_{\text {observe }}$ (Lo) for the placebo group amounted to 0.20 and Lobserve for the energy drink group was 0.1889 , while $\mathrm{L}_{\text {table }}$ at $\alpha 0.05$ and $\mathrm{N}=18$ was 0200 . The $\mathrm{L}_{\text {observe }}<\mathrm{L}_{\text {table }}$ can then be concluded that the data of the group in this study is unqualified from the normal distribution population. For more details can be seen in table 3.

Table 3 Data Normality test Results

\begin{tabular}{lllll}
\hline Groups & $\mathrm{N}$ & $\mathrm{L}_{\text {observe }}$ & $\mathrm{L}_{\text {table }}$ & Decision \\
\hline Placebo & 18 & 0.20 & 0.200 & Normal \\
Energy Drink & 18 & 0.1889 & 0.200 & Normal \\
\hline
\end{tabular}




\section{Homogeneity Test}

A homogeneity test is performed using an $\mathrm{F}$ homogeneity test, as the group in the study consists of 2 groups of placebo and an energy drink group. Based on the test of homogeneity that has been done then obtained variance (S2) placebo group amounting to 1.02 and variance $\left(\mathrm{S}^{2}\right)$ in the energy drink group of 1.19 whereas $F_{\text {table }}$ at $\alpha 0.05$ is $2.29, F_{\text {observed }}<F_{\text {table }}$ then can be concluded that both data In this homogeneous study. For more details, the results of the homogeneity test can be seen in table 4 .

Table 4 Homogeneity test Results

\begin{tabular}{llllll}
\hline Groups & $\mathrm{N}$ & Variants $\left(\mathrm{S}^{2}\right)$ & $\mathrm{F}_{\text {observe }}$ & $\mathrm{F}_{\text {table }}$ & Decision \\
\hline Placebo & 18 & 1.02 & & & \\
Energy Drink & 18 & 1.19 & 1.160 & 2.290 & Homogenous \\
\hline
\end{tabular}

\section{Hypothesis Test}

Hypotheses in this study are influences given by placebo and significantly different energy drinks. Based on the analysis of data obtained, an average placebo group increase by 1.03 and an average increase in energy drink group by 1.19 and based on hypotheses test using TTest obtained tobserved 0.14 whereas ttable at $\alpha 0.05$ is of 1.69 then tobserved $0.14<$ table 1.69 . Thus, it can be concluded that the influence given by placebo and energy drinks did not differ significantly. For more clarity can be seen in table 5.

Table 5 Hypothesis Testing

\begin{tabular}{llllll}
\hline Groups & $\mathrm{N}$ & Average & $\mathrm{T}_{\text {observed }}$ & $\mathrm{t}_{\text {table }}$ & Decision \\
\hline Placebo & 18 & 1.03 & 0.14 & 1.69 & No significant difference \\
Energy Drink & 18 & 1.19 & & & \\
\hline
\end{tabular}

\subsection{DISCUSSION}

From the above hypothesis testing, it can be obtained that the average enhancement of aerobic endurance capabilities in a group given a placebo with a group given the consumption of energy drinks is not significantly different, so The proposed research hypothesis was rejected empirically. Therefore it can be said that the influence given by placebo and energy drinks to increase aerobic endurance is the same. It answers the questions in society and among students, whether it is true that energy drinks can improve the ability of aerobic endurance, as it is believed by some students and society. Drinks are drinks that refresh consumers with a combination of sugar, cafes, and other ingredients ${ }^{5}$. If viewed from the composition listed on the packaging of energy, beverage products will be seen as various kinds of substances that can improve the physical ability. However, it still needs to be conducted clinically testing so that the community especially, students, are not mistreated in the consumption of substances containing supplements.

Placebo is something that can change the psychological response of a person ${ }^{1}$, a placebo given in the study was regular mineral water without the presence of any substance mixture of $500 \mathrm{ml}$ so that the placebo could not enhance aerobic endurance ability. Placebo was conducted before data retrieval. The presence of control with the use of placebo in this research and from the results of statistical data analysis proves that the improvement occurring against the ability of aerobic endurance after consuming energy drinks is caused by suggestive from within the students who are influenced by the advertising of energy drinks in the bar and print media and online that energy drinks can improve the ability of aerobic endurance. Energy drinks promotion through printed and electronic media can have an impact on improving the physical condition so that many people who trust the advertisement and consume energy drinks before doing physical activity in hopes of improving their physical abilities include aerobic endurance. Some energy drink products do contain some substances that can affect human physical such as caffeine, taurine, vitamins, and others. However, from the results of this research, it can be said that increasing aerobic endurance is more due to suggestive from the students, and this incident is very prevalent because the suggestion can affect the students' strength. The suggestion is a programming component of the unconscious human mind that can increase power and strength ${ }^{11}$. Suggestive can stimulate the human mind so that people do according to what is in his mind. Placebo as control also provides a suggestion for students through the information provided by researchers before the placebo was administered so that both substances (placebo and energy drinks) exerted an influence on the increase in aerobic endurance, and the difference in both effects can be said to be the same.

\subsection{CONCLUSION}

Based on the data analysis and discussion above, it can be concluded that placebo and energy drinks can improve the aerobic endurance, and enhancement capabilities provided by both substances are not significantly different. So, it can be said that a suggestion from within a student causes the improvement occurring in the group that consumes energy drinks. 


\section{Reference}

Stewart-Williams, S. 2004. The Placebo Puzzle: Putting Together The Pieces. Health Psychology, 23, 198-206.

Stewart-Williams, S., and Podd, J. (2004). The Placebo Effect: Dissolving The Expectancy Versus Conditioning Debate. Psychology.Bulletin, 130, 324-340

Clark VR, Hopkins WG, Hawley JA, Burke LM. (2000). Placebo Effect Of Carbohydrate Feeding During A 4-Kmcycling Time Trial. Medical Science Sports Exerc, $32,1642-1647$

B Saunders., L. F. de Oliveira., R. P da Silva., V. de SallesPainelli., L. S Goncalves., G. Yamaghuci., T. Mutti., E. Maciel., H. Roschel., G. G. Artioli., B. Gualano. (2017). Placebo In Sports Nutrition: A Proof-Of-Principle Study Involving Caffeine Supplementation. Scandinavian Journal of Medicine\& Science In Sports, 27, 1240-1247.

Martina, M Cartwright. (2013). The Stimulating Truth About Energy Drinks. IDEA Fitness Journal, 3, 76-80

Roberta Luksevicius Rica, et, al. (2019). Energy Drinks Do Not Alter Aerobic Fitness Assessment Using Field Tests In Healthy Adults Regardless Of Physical Fitness Status. Journal of Physical Education and Sport. 19(1), 113-120.

Mitchel, A. Magrini., Ryan J. Colquhoun., J. Jay Dawes., Doug B. Smith. (2016). Effects of a Pre-workout Energy Drink Supplement on Upper Body Muscular Endurance Performance. International Journal of Exercise Science. 9(5), 667-676.

Bill Campbell., Jasmine Richmond, J. Jay Dawes. (2016). The Effects of a Commercial, Pre-exercise Energy Drink Supplement on Power, Muscular Endurance, and Repeated Sprint Speed. International Journal of Exercise Science, 9(2), 205-213.

Junusul, Hairy. (2003). Aerobic Endurance. Jakarta: Directorate General of Sports Department of National Education.

Lamb, David R. (1984). Physiology Of Exercise. USA: Macmillan Publishing Company

Trinurmi, Sitti. (2014). The Influence Of Sugestion In Achieving Student Learning Achievement. Jurnal Bimbingan Penyuluhan Islam. 1(1), 1-97 